\title{
A Case Control Study of Hematological Changes in Children with Protein Energy Malnutrition Attending Gauhati Medical College and Hospital.
}

\author{
Dr. EsengKhyoGohain*, Dr. KumudPathak**, Dr. BijuChoudhury* \\ *Deptt. Of Physiology, ** Deptt.Of Pediatrics, Gauhati Medical College\&Hospital, Guwahati, Assam
}

\begin{abstract}
Background:Protein Energy Malnutrition (PEM) is associated with lot of changes in the body. In hematological system some degrees of anemia, changes in reticulocyte response, erythroid activity have been described in literatures. But the observations regarding hematological changes in children with PEM have been inconsistent. Existing literatures describe mostly about anemia but changes of other cell line like leukocytes and platelets have not been described well. Moreover regarding anemia, most of the literatures have described changes mostly in severe form of malnutrition which only forms the tip of the iceberg. So there is scope for study of hematological changes in the non-severe form of PEM also.

Methodology: The Case control study was done during a period of one year from August 2013 to August 2014 in Gauhati Medical College. One hundred children in the age group of 6-59 months were selected on the basis of their nutritional status classified by Indian Academy of Pediatrics classification of PEM. Controls were taken randomly from healthy children with normal nutritional status attending Pediatric clinic for immunization or routine checkup. Complete blood count was performed by automated Analyzer Sysmex XS 800i in hematology laboratory and peripheral blood smear and platelet count were done by manual method at physiology laboratory. To find out the type of anemia respective tests were done if indicated and feasible. Grading of anemia was found out using WHO criteria. Data were analyzed with the help of Microsoft excel and Epi info version 7 software packages (2014) . Chi-square test and student t-test were used to test for statistical significance of the difference. A p value of $<0.05$ was regarded as significant.

Results: Anemia was a constant feature of PEM as that has been reported by previous studies. The cases have lower mean value of hemoglobin and hematocrit as compared to controls. There were statistically significant lower mean values for RBC indices like RBC count, MCH and MCHC in children with PEM when compared to the controls ( $p<.0001)$. We found a significant leukocytosis among children with PEM compared to controls. The cases had higher mean value of Neutrophil and lower mean value of lymphocyte compared with controls. There was a statistically significant difference in platelet count between cases and controls. Cases had more mean value of platelet counts than controls. Ninety one percent of the children with PEM are anemic and most of them were moderate to severely anemic (73.6\%). The cases had almost equal distribution of microcytic (34\%), macrocytic (32.9\%) and normocytic (31.8\%) anemia whereas in the controls most common anemia found was microcytic anemia (46.8\%).
\end{abstract}

Conclusion:Children with PEM had lower mean value of Hemoglobin, Hematocrit and red cell indices and higher mean values of total WBC and platelets. Most of the children with PEM were moderate to severely anemic. There was equal distribution of normocytic, macrocytic and microcytic anemia in children with PEM.

\section{Introduction}

PEM as a range of pathological conditions arising from co-incidental lack in varying proportions of protein \& calories occurring most frequently in infants and young children and commonly associated with infection. ${ }^{1}$ Protein Energy Malnutrition results in widespread alterations in organ and system function. ${ }^{2}$ In haematological system, changes affect all the blood cells. Some degrees of anaemia, changes in reticulocyte response, erythroid activity have been described in literatures. Hemopoiesis depends on the microenvironment of the marrow. ${ }^{3,4}{ }^{4,5}$ The sheer need for protein by the process of hemopoiesis could in itself justify the occurrence of anaemia and leucopenia which are frequently encountered in PEM. The lack of iron has been considered as being the main cause of anaemia in malnutrition. ${ }^{6}$ However some studies demonstrate that a decrease in erythropoietin, occurring due to the reduced ingestion of protein and reduced red cell production in adaptation to a smaller lean body mass may also be responsible for anaemia. ${ }^{7,8,9}$ Leucopenia and leucocytosis are situations that have been described in literature as it is usually accompanied by infectious processes or chronic disease. ${ }^{10,11,12}$ Protein deficiency leads to lymphopenia, thymus, spleen and lymph node involution, which is particularly intense in the thymus and spleen. ${ }^{13}$

But the inconsistent observations regarding hematological changes in children with PEM have limited the usefulness of these parameters in the anticipatory care of these patients. ${ }^{14}$ Most of the existing literatures 
describe mostly about anemia but changes of other cell line like leukocytes and platelets have not been described well. Moreover regarding anemia, most of the literatures have described changes mostly in severe form of malnutrition (viz kwashiorkor and marasmus) which only forms thetip of the iceberg. So there is scope for study of hematological changes in the non-severe form of PEM also.

\section{Materials and Methods}

The case control study was done in the departments of Pediatrics, physiology and hematology of Gauhati Medical College during a period of one year from August 2013 to August 2014. A pre designed Performa consisting of necessary queries/questionnaires was used to obtain information from the parents/guardian. A total of 200 subjects with equal number of cases and controls were selected for the study. Ethical clearance was taken from institution ethical committee and written consents were taken from parents.

Patient inclusion criteria:Cases in the age group of 6-59 months were selected on the basis of their nutritional status according to Indian Academy of Pediatrics classification of PEM. Controls were taken randomly from children with normal nutritional status without hematological or infectious conditions. Malnutrition cases secondary to systemic illness were excluded from the study.

Hematological examination:Complete blood count was performed by automated AnalyserSysmex XS 800i in hematology lab and peripheral blood smear and platelet count were done by manual method at physiology lab. EDTA anti-coagulated fresh venous samples were used. To find out the type of anemia respective tests were done if indicated and feasible. Grading of anemia was found out using WHO criteria. In samples where platelet count report was doubtful platelet was again examined in PBS and was recounted manually.

\section{Statistics:}

Data were analyzed with the help of Microsoft excel and Epi info version 7 software packages (2014) .Chisquare test and student $t$-test were used to test for statistical significance of the difference. A p value of $<0.05$ was regarded as significant. Analysis of variance (ANOVA) was used for some comparisons.

\section{Results}

A total of 200 children, 100 cases of Protein Energy Malnutrition and 100 controls of healthy children were studied. The mean age of children with PEM was $24.05 \pm 14.67$ months.

The mean hemoglobin values for the cases and controls were $8.83 \pm 1.60 \mathrm{gm} / \mathrm{dl}$ and $11.58 \pm 1.58 \mathrm{gm} / \mathrm{dl}$ respectively while their mean hematocrit values were $28.83 \pm 4.95 \%$ and $35.08 \pm 4.36 \%$ respectively and the differences were statistically significant $(\mathrm{p}<0.0001)$. The mean values of RBC in cases and controls were $3.81 \pm 0.74 \times 10^{6}$ cells $/ \mathrm{mm}^{3}$ and $4.51 \pm 0.69 \times 10^{6}$ cells $/ \mathrm{mm}^{3}$ respectively and the difference was statistically significant $(\mathrm{p}<0.0001)$.The mean values of mean corpuscular volume $(\mathrm{MCV})$ were $77.96 \pm 11.99 \mathrm{fl}$ and $78.56 \pm 10.30 \mathrm{fl}$ in the cases and controls respectively and the differences were not significant $(\mathrm{p}=0.7043)$. The mean values for $\mathrm{MCH}$ and MCHC were $24.07 \pm 3.63 \mathrm{pg}$ and $30.96 \pm 2.84 \mathrm{gHb} / \mathrm{dl} \mathrm{RBC}$ for cases and 26.16 \pm 3.60 $\mathrm{pg}$ and $33.27 \pm 2.37 \mathrm{gHb} / \mathrm{dl} \mathrm{RBC}$ for controls and both were statistically significant $(\mathrm{p}<0.0001)$.

The mean value of WBC in cases was $14.84 \pm 7.54 \times 10^{3}$ cells $/ \mathrm{mm}^{3}$ and $9.71 \pm 4.08 \times 10^{3}$ cells $/ \mathrm{mm}^{3}$ among the controls. This value was significant $(\mathrm{p}<0.0001)$. The cases had higher mean value of Neutrophil and lower mean value of lymphocytes compared with controls although they were not significant.

The mean values of platelets counts were $(375.8 \pm 153.1) \times 10^{3}$ cells $/ \mathrm{mm}^{3}$ and $(217.9 \pm 876.5) \times 10^{3}$ cells $/ \mathrm{mm}^{3}$ for the casesand the controls respectively and the difference was statistically significant $(\mathrm{p}<$ 0.0001).( Table 1)

Table 1: Hematologic profile of the cases (PEM) versus the controls.

\begin{tabular}{|c|c|c|c|c|c|c|c|c|}
\hline Parameters & \multicolumn{2}{|c|}{ Case } & \multicolumn{2}{|c|}{ Control } & \multicolumn{3}{|c|}{ Unpaired t-test } & Comment \\
\hline $\mathrm{Hb}(\mathrm{gm} / \mathrm{dl})$ & 8.83 & 1.60 & 11.58 & 1.58 & 12.174 & 197 & $<0.0001$ & Significant \\
\hline $\operatorname{HCT}(\%)$ & 28.83 & 4.95 & 35.08 & 4.36 & 9.367 & 194 & $<0.0001$ & Significant \\
\hline TC $($ cell $/ \mathrm{cmm})$ & 14838 & 7535 & 9712.9 & 4078.4 & 5.982 & 152 & $<0.0001$ & Significant \\
\hline $\mathrm{N}(\%)$ & 50.64 & 17.67 & 46.35 & 14.15 & 1.888 & 189 & 0.0606 & Not significant \\
\hline $\mathrm{L}(\%)$ & 37.04 & 15.07 & 40.55 & 13.76 & 1.721 & 196 & 0.0868 & Not significant \\
\hline $\mathrm{M}(\%)$ & 8.54 & 4.02 & 9.34 & 5.46 & 1.172 & 181 & 0.2427 & Not significant \\
\hline $\mathrm{E}(\%)$ & 3.27 & 3.70 & 3.44 & 4.96 & 0.2473 & 183 & 0.8050 & Not significant \\
\hline Platelet(cell/cmm) & 375816 & 153180 & 217970 & 87650 & 8.944 & 157 & $<0.0001$ & Significant \\
\hline lioncells/cmm) & 3.81 & 0.74 & 4.51 & 0.69 & 6.893 & 198 & $<0.0001$ & Significant \\
\hline $\mathrm{MCV}($ & 77.96 & 11.99 & 78.56 & 10.30 & 0.3801 & 198 & 0.7043 & ificant \\
\hline $\mathrm{MCH}(\mathrm{Pg})$ & 24.07 & 3.63 & 26.16 & 3.60 & 4.067 & 198 & $<0.0001$ & cant \\
\hline MCHC (gHb/dl) & 30.96 & 2.84 & 33.27 & 2.37 & 6.245 & 198 & $<0.0001$ & Significant \\
\hline
\end{tabular}

DOI: $10.9790 / 0853-1510012529$

www.iosrjournals.org

$26 \mid$ Page 
Among the cases, 91(91\%) were anemic and only $9(9 \%)$ had no anemia. Twenty four (24\%) had mild grade of anemia, $53(53 \%)$ had moderate anemia and $14(14 \%)$ had severe anemia. Among the controls 68 (68\%) had no anemia, $23(23 \%)$ had mild, $8(8 \%)$ had moderate and only 1 (1\%) had severe anemia. These differences were also significant $(\mathrm{p}<0.0001)$.he cases had almost equal distribution of microcytic hypochromic (31\%), macrocytic (30\%) and normocytic normochromic type of anemia (29\%). Only 1 case (1\%) had dimorphic anemia. Among controls, 15 (15\%) had microcytic hypochromic, 9 (9\%) had normocytic normochromic and $8(8 \%)$ had macrocytic anemia. These differences were significant $(\mathrm{p}<0.0001)$.

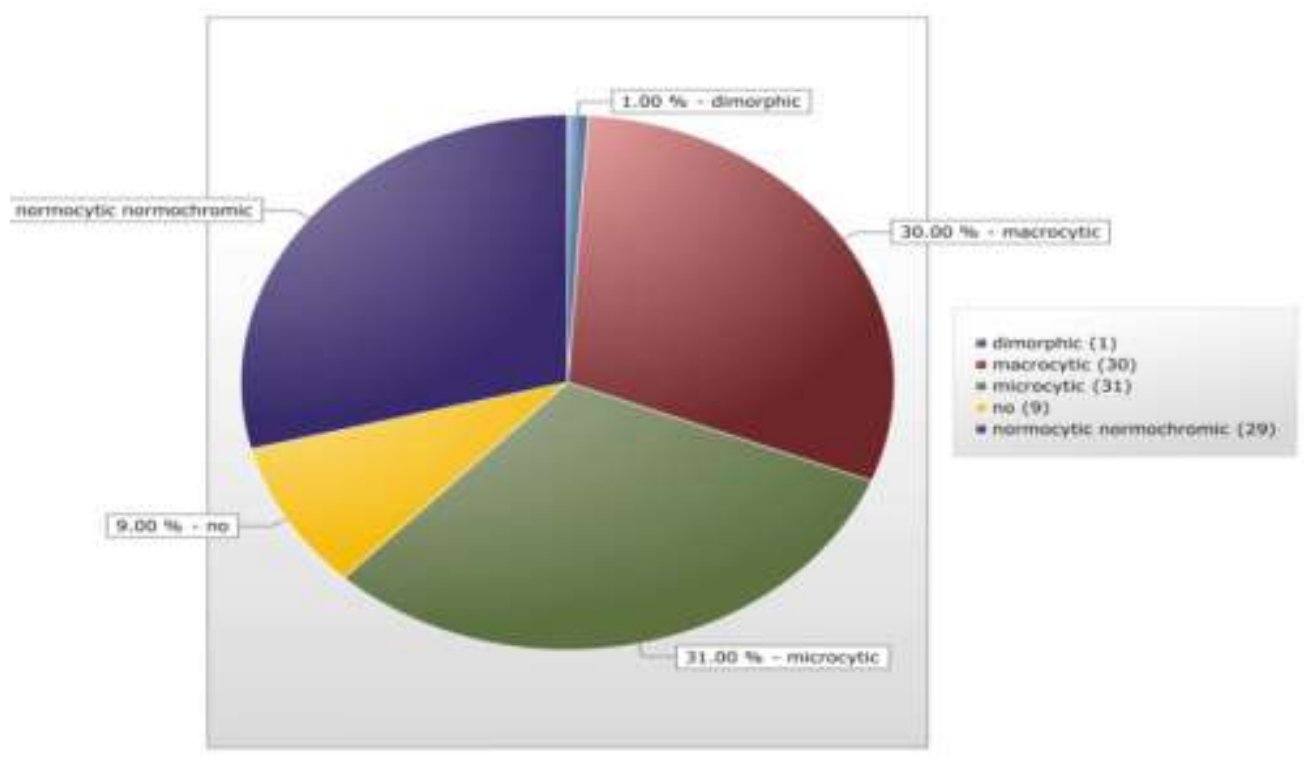

Fig 1: frequency of different type of anemia in PEM group

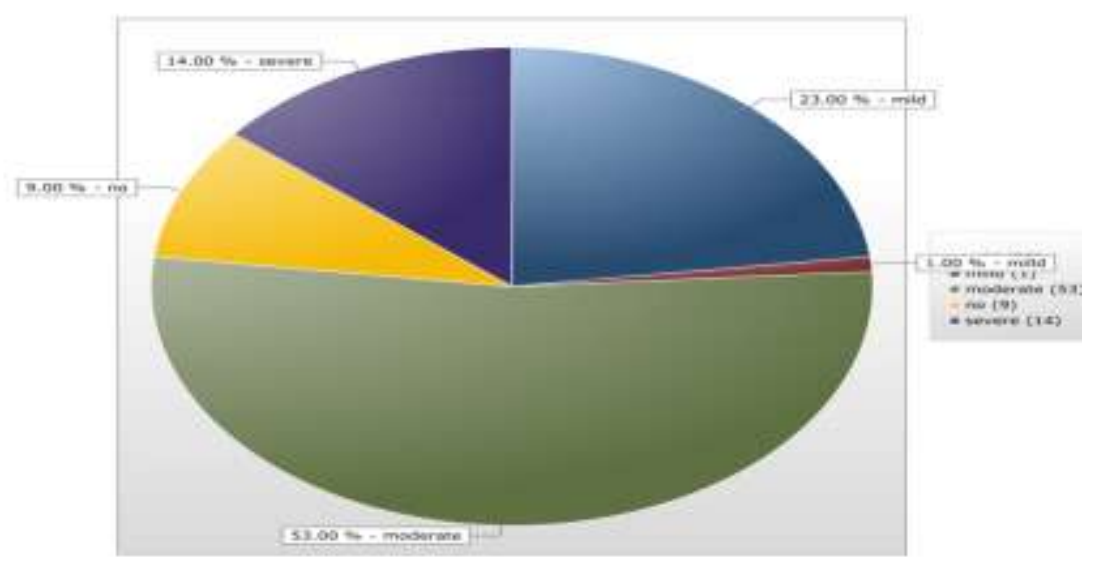

Fig 2: Frequency of different grade of anemia in PEM group.

\section{Discussion}

In this study the mean age of children with PEM was $24.05 \pm 14.67$ months. In a study done by Saka O et al the mean age of children with PEM was $22.7 \pm 14.40$ which is almost equal to present study. ${ }^{15}$

The study confirms that anemia is a constant feature of PEM as that has been reported by previous studies. These findings are consisted with previous studies. Saka et al also found the same result. ${ }^{15} \mathrm{The}$ mean $\mathrm{Hb}$ level in cases in the present study was $8.83 \pm 1.60 \mathrm{gm} / \mathrm{dl}$. This value is lower than what Saka et al found $(10.1 \pm$ $2.1 \mathrm{gm} / \mathrm{dl}) .{ }^{15}$ But the lower mean values of the hematocrit and hemoglobin in children with PEM in comparison to controls is a finding that is similar to previous studies ( Saka et al, Laditan et al ${ }^{16}$, El Nawawy $\mathrm{S}$ et al ${ }^{17}$ ) .This study has shown statistically significant lower mean values for RBC indices like RBC count, MCH and MCHC in children with PEM when compared to the controls. This is in consistent with Saka et al study. ${ }^{15}$ But the mean of MCV was almost similar in case and controls. This is not in consistent with Saka et al study. 
In this study, we found a significant leucocytosis among children with PEM compared to controls. Leucocytosis in these children may be a result of infection which is seen commonly in PEM. The cases had higher mean value of Neutrophil and lower mean value of lymphocyte compared with controls although the differences were not significant. However, several other studies have shown leucopenia as well as neutropenia as a common finding in malnutrition. ${ }^{18,19,20}$ The lower lymphocyte count observed in the present study and other studies can be attributed to the fact that thymus size gets reduced in children during severe PEM. ${ }^{15}$

An important finding in the present study was a statistically significant difference in platelet count between cases and controls. Cases had more mean value of platelet counts than controls. In a study done by AbdurRehman et al (2001) they found that the mean platelet count was increased at the beginning compared to those of after therapy and to the control. ${ }^{21}$ But this finding is in contrast to the finding of Saka et al and Uner et al where they found low platelet count in cases. ${ }^{15,22}$ so more studies regarding the changes in platelet count is needed.

In the present study $91 \%$ of the children with PEM are anemic and most of them were moderate to severely anemic $(73.6 \%)$, whereas only $32 \%$ of the controls were anemic and most of them were mildly anemic (71.8\%). In a study done by Ozkale et al (Turkey, 2014) anemia was detected in $97 \%$ of patients with PEM and the major cause of anemia was hypochromic microcytic in this study. ${ }^{23}$ In a recent study done by Thakur et al in New Delhi (2014), of the 131 patients with SAM, 81.1\% had anemia. $67.3 \%$ of these had severe anemia and $13.8 \%$ had moderate anemia. ${ }^{24}$ In another Indian study by R. Kumar et al (Madhya Pradesh, 2013) 88.5\% children had anemia, $7.6 \%$ had mild anemia, $55.7 \%$ had moderate anemia and $24 \%$ had severe anemia. ${ }^{25}$ in a study done by Ubesie et al (in Nigeria 2012), they found severe anemia in $24.2 \%$ of the patients with PEM. ${ }^{26}$

The cases had almost equal distribution of microcytic (34\%), macrocytic $(32.9 \%)$ and normocytic $(31.8 \%)$ anemia whereas in the controls most common anemia found was microcytic anemia (46.8\%). In their study, Thakur et al got the most common type of anemia as microcytic anemia (38.6\%) followed by megaloblastic anemia $(30.5 \%){ }^{24}$

\section{Conclusion}

This study confirms that anemia is a near constant feature of PEM. There was nearly equal prevalence of microcytic hypochromic, macrocytic and normocytic normochromic anemia in the PEM cases. This may be explained by the fact that there is no iron deficiency or actually iron store may be more in cases of PEM. But during recovery stage only there may be relative deficiency of iron. In this regard more studies are needed. As megaloblastic anemia closely follows microcytic anemia, supplementation with vitamin B12 in addition to iron and folic acid may be recommended as was suggested by Thakur et al (2014). Most of the children in PEM group suffer from moderate to severe anemia. Significant leukocytosis was seen among children with PEM. In this study we observed a significantly high mean value of platelet in PEM group compared to controls. More studies are needed in this issue to know what exactly happens to platelet count at different stages of malnutrition.

\section{References}

[1]. WHO :Work TH, Ifekwunigwe A, Jelliffe DB, Jelliffe P, NeumanCG.Tropical problems in nutrition. Ann Intern Med 1973; 79: 707-711.

[2]. Waterlow JC. Classification and definition of protein calorie malnutrition. British Medical Journal. 1972; 3: 566-9.

[3]. Quesenberry PJ. Hemopoietic stem cells, progenitor cells, and citokines. In: Willians hematology. Editors: Beutler E, Lichtmsn M, Coller BS, Kipps TJ. 5 edn. New York: McGraw Hill. 1995. p. 211-228.

[4]. Mckenna SL, Cotter TG. Functional aspects of apoptosis in hematopoiesis and consequences of failure. Adv Cancer Res 1997; 71:121-164.

[5]. Cowling GJ, Dexter TM. Apoptosis in the haemopoietic system. In: The role of apoptosis in development, tissue homeostasis and malignancy. Editors: Dexter TM, Raff MC, Wyllie AH. London: Chapman \& Hall. 1995. p. 21-27.

[6]. Finch CA. Erythropoiesis in protein-calorie malnutrition. In: Protein-Calorie malnutrition. Editor: Olson RE. New York: Academia Press 1975. p. 247-256.

[7]. Aschkenasy A. Effect of a protein-free diet on lymph node and spleen cell response in vivo to blastogenicstimulantes. Nature 1975; 254:63-65.

[8]. Mary EP. Protein Energy Malnutrition, pathophysiology, clinical consequences and treatment .In:Walker A W ,Christopher D, Watkim J B eds. Nutrition in Paediatrics. London. Blackwell Waterson. 2008; 171184. 
[9]. Warrier RP. The anemia of malnutrition. In: Suskind RM, Suskind LL, eds. The malnourished child. New York, Lippincott-Raven, 1990; 19:61-72.

[10]. Catchatourian R, Eckerling G, Fried W. Effect of short-term protein deprivation on hemopoietic functions of healthy volunteers. Blood 1980; 55:625-628.

[11]. Gross Rl, Newberne MP. Role of nutrition in immunologic function. Physiol Rev 1980; 60:188-302.

[12]. Rosen E, Buchanan N, Hansen JD. Letter: Evolution of kwashiorkor and marasmus. Lancet 1974;2:458

[13]. Chandra RK, Kumari S. Nutrition and immunity: an overview. J Nutr 1994;124:1.433S-1.435S

[14]. UNICEF State of the World's children: Official publication of the United Nations. 2005. 85-88.

[15]. Saka A .O et al: Haematological Profile in Children with Protein Energy Malnutrition in North Central Nigeria in Global Journal of Medical Research Volume 12 issue 4 version 1.0 May 2012.

[16]. Laditan AAO, Tindimebwa G. The Protein Energy Malnourished Child in a Nigerian Teaching Hospital. J. Trop. Pediatr 1983; 29: 61-64 .

[17]. El-Nawawy S, Barakat T, Elwalily A, Abdel-MoneimDeghady and M. Hussein. Evaluation of erythropoiesis in Protein Energy Malnutrition East Med Health J.2002; 8: 2-3.

[18]. Nathan DG. Regulation of hematopoiesis. Pediatric research. 1990; 27:423-7.

[19]. Edozien, J.C., Khan,M.A. R. \&Waslien,C. L. Human protein deficiency:results of a Nigerian village study. J. Nutr 1976:106: 312-028.

[20]. Fondu P, Hariga Muller C, Mozes N, Neve J, Van Steirteghem A, Mandelbaum IM. Protein-energy malnutrition and anemia in Kivi. Am J ClinNutr 1978; 31:46-56.

[21]. Abdurrehman et al Clinical \& Applied Thrombosis/Hemostasis;Oct2001, Vol. 7 Issue 4, p286

[22]. Uner A, Calişkan U, Oner AF, Koç H, Kasap AF. Platelet functions in patients with protein-energy malnutrition. ClinApplThrombHemost. 2001 Oct;7(4):286-8

[23]. Ozkale M, Sipahi T : Hematologic and bone marrow changes in children with protein-energy malnutrition. PediatrHematolOncol. 2014 May; 31(4):349-58. doi: 10.3109/08880018.2013.813098. Epub 2013 Aug 29.

[24]. Thakur N, Chandra J, Pemda H et al. Anaemia in severe acutemalnutrition. Nutrition. 2014 Apr; 30(4):440-2. doi: 10.1016/j.nut.2013.09.011. Epub 2013 Oct.

[25]. Rakesh Kumar, Jyoti Singh, Karan Joshi et al.Co-morbidities in Hospitalized Children with Severe Acute Malnutrition. Indian Pediatrics, August 2013.

[26]. Agozie C Ubesie, Ngozi S Ibeziako, Chika I Ndiokwelu et al. Under-five protein energy malnutrition admitted at the University of Nigeria Teaching Hospital, Enugu: a 10 year retrospective review. Nutrition Journal 2012, 11:43. 